\title{
Fortunat Joos
}

Climate and Environmental Physics, Physics Institute, University of Bern, Bern, Switzerland; joos@climate.unibe.ch

Many books and articles deal with the numerous feedbacks and links in the climate-biogeochemical system and their consequences for our society. Here, the focus is on one particular link between the physical climate system and biogeochemical cycles, that is, the radiative forcing imposed on the physical climate system through altered greenhouse gas concentrations and other radiative perturbations.

Polar ice cores analysed by different groups around the world leave no doubt that cold polar ice faithfully records past atmospheric concentrations of major greenhouse gases (Fig. 1 over page) (Stauffer et al., 2002). The wellknown finding is that the rate of increase in atmospheric carbon dioxide and methane is without precedence at least over the past few tens of millennia, and that $\mathrm{CO}_{2}$ and $\mathrm{CH}_{4}$ concentrations today are larger than at any time over the past 650,000 years, the period spanned by the ice core records. Atmospheric concentration of $\mathrm{N}_{2} \mathrm{O}$, another greenhouse gas, is also higher than ever measured, though its ice core record is less complete. Humans, by burning fossil fuels and through land use changes and other activities, are altering the state of the atmosphere.

Increasing concentrations of greenhouse gases cause global warming. Greenhouse gases such as $\mathrm{CO}_{2}$ absorb part of the long-wave radiation emitted from the earth surface, thereby altering the temperature on the ground and the temperature distribution in the atmosphere. The greenhouse gas theory was already well established in the 19th century and by the end of the century, Arrhenius had calculated that a doubling of the atmospheric $\mathrm{CO}_{2}$ concentration would cause a globalmean surface warming of about $4^{\circ} \mathrm{C}$. In comparison, this climate sensitivity, termed $\Delta \mathrm{T}_{2 x^{\prime}}$ evaluated with the current set of comprehensive and spatially-resolved climate models falls generally within the range of 1.5 to $4.5^{\circ} \mathrm{C}$.

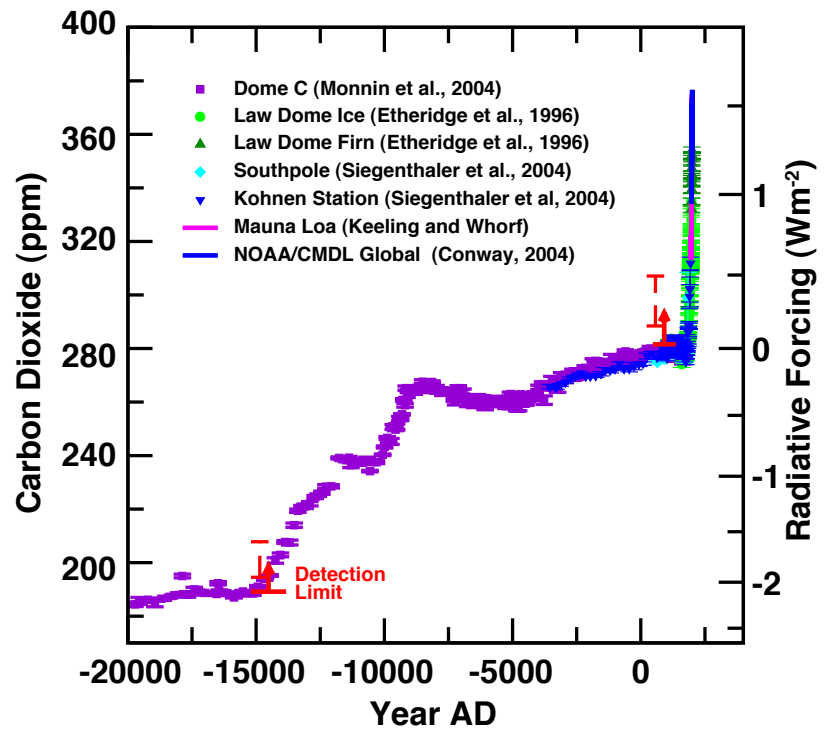

Climate scientists use a concept termed 'radiative forcing' to compare the climatic influence of a variety of greenhouse gases, as well as that of other radiative agents such as aerosols or other externally imposed perturbations on the radiative energy budget of the planet (Ramaswamy et al., 2001). The basic concept of radiative forcing is relatively simple: It is the change in the radiation flux entering the lower atmosphere-surface system through the tropopause immediately after a perturbation (e.g. after a step-like increase in atmospheric $\mathrm{CO}_{2}$ ).

The definition of radiative forcing is not without complexity and slightly different versions are found in the literature. IPCC uses the following: "The radiative forcing of the surface-troposphere system due to the perturbation in or the introduction of an agent (say, a change in greenhouse gas concentrations) is the change in net (down minus up) irradiance (solar plus long-wave; in $\mathrm{Wm}^{-2}$ ) at the tropopause after allowing for stratospheric temperatures to readjust to radiative equilibrium, but with surface and tropospheric temperatures and state held fixed at the unperturbed values". Radiative forcing is typically on the order of a few Watts per square meter $\left(\mathrm{W} \mathrm{m}^{-2}\right)$. For example, a doubling of the pre-industrial $\mathrm{CO}_{2}$ concentration from $280 \mathrm{ppm}$ to 560 ppm causes a radiative forcing, $R F\left(2 \times \mathrm{CO}_{2}\right)$, of $3.7 \mathrm{~W} \mathrm{~m}^{-2}$.

Climate feedbacks such as the change in water vapour and cloud cover in response to climate change are not included in the definition of radiative forcing. The strength of these climate feedbacks defines the climate sensitivity. The change in global mean surface temperature, $\Delta \mathrm{T}_{\mathrm{s}, \alpha}$ and radiative forcing, $R F$, are linked through the equilibrium climate sensitivity, $\Delta \mathrm{T}_{2 \mathrm{x}}$. When the climate system has reached a new (quasi-) equilibrium, the change in surface temperature equals the product of the climate sensitivity and the change

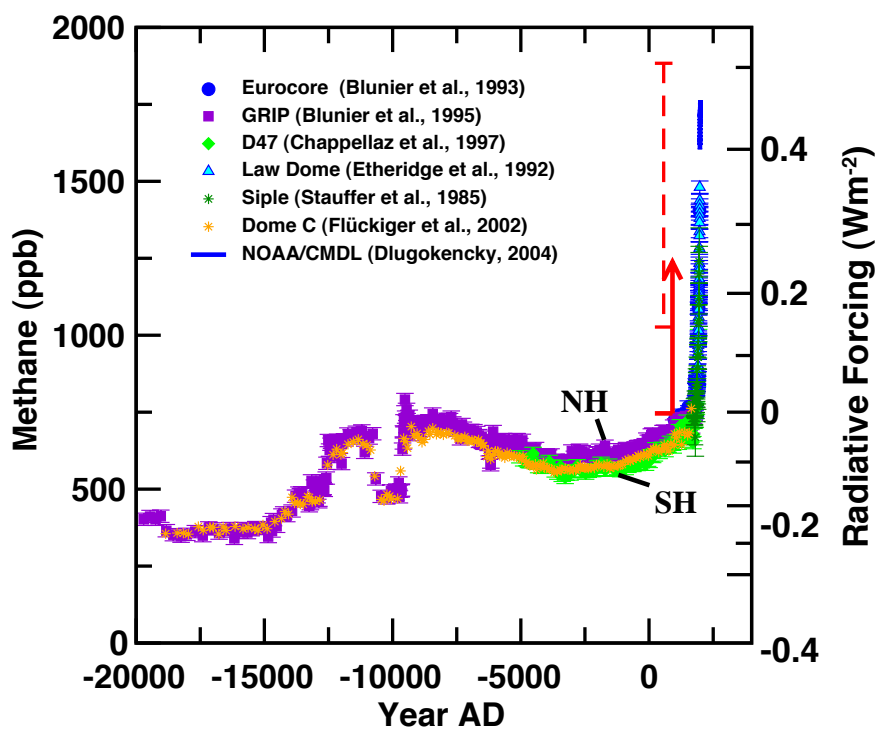

Figure 1: Evolution of atmospheric $\mathrm{CO}_{2}$ (right) and $\mathrm{CH}_{4}$ (left) over the last 20,000 years. Right-hand axes show radiative forcing relative to 1750 A.D. associated with the concentration changes as calculated from Table 1. Note that the radiative forcing scale is non-linear. Red arrows indicate the theoretical detection limit of a forcing (relative to Last Glacial Maximum and pre-industrial conditions) within a climate system model, assuming an internal climate variability or detection threshold of $0.2^{\circ} \mathrm{C}$, climate equilibrium, and a mid-range climate sensitivity of $3^{\circ} \mathrm{C}$. Dashed red arrows indicate the uncertainty of the detection threshold associated with the climate sensitivity range of 1.5 to $4.5^{\circ} \mathrm{C}$. 
in radiative forcing divided by $R F\left(2 \times \mathrm{CO}_{2}\right)$ :

(1) $\Delta T_{s \infty}=\Delta T_{2} x \frac{R F}{\mathrm{P} \Phi\left(2 \xi \mathrm{XO}_{2}\right)}$

Calculations of radiative forcing are done in a 3-D setting taking into account the non-uniform distribution of temperature, pressure and of other variables in the atmosphere, as well as the absorption spectrum of individual molecules. The radiative forcing fields vary over space and time. It has been shown that the globally and annually averaged radiative forcing provides a good measure for the resulting surface temperature changes even for forcings with very different spatial distributions. Table 1 provides a set of equations that allows the direct estimation of the radiative forcing relative to the pre-industrial period or any other reference for the most common greenhouse gases. These formulations summarise the results of comprehensive radiation models (Ramaswamy et al., 2001). $\mathrm{CO}_{2}$ forcing increases logarithmically with concentration as $\mathrm{CO}_{2}$ is relatively abundant and self-shading effects occur. Radiative forcing by $\mathrm{CH}_{4}$ and $\mathrm{N}_{2} \mathrm{O}$ increases with the square root of the concentration. This means that an identical concentration increase is more effective at lower concentrations than at higher concentrations for these three gases. On the other hand, radiative forcing increases linearly with concentration for gases with a low abundance such as halocarbons and $\mathrm{SF}_{6}$. These gases have been added to the atmosphere by humans only over recent decades.

Radiative forcing can be calculated over the paleorecord from ice core concentrations. Figure 1 details the evolution of $\mathrm{CO}_{2}$ and $\mathrm{CH}_{4}$ and their radiative forcing over the last deglaciation and the current warm period, the Holocene. Atmospheric $\mathrm{CO}_{2}$ increased from about $190 \mathrm{ppm}$ at the Last Glacial Maximum to about $265 \mathrm{ppm}$ at the beginning of the Holocene. Variations during the Holocene were small. Similarly, $\mathrm{CH}_{4}$ increased by about 350 ppb over the transition and underwent modest changes during the Holocene. Natural fluctuations of $\mathrm{CO}_{2}$ and $\mathrm{CH}_{4}$ have remained within relatively narrow limits during glacial/ interglacial cycles. Their concentrations have stayed below $300 \mathrm{ppm}$ and $800 \mathrm{ppb}$, respectively. In contrast, over less than two centuries, atmospheric $\mathrm{CO}_{2}$ has increased by almost $100 \mathrm{ppm}$ and $\mathrm{CH}_{4}$ by $1,000 \mathrm{ppb}$. The radiative forcing (relative to 1750 A.D.) by $\mathrm{CO}_{2}$ was $-2 \mathrm{~W} \mathrm{~m}^{-2}$ at the Last Glacial Maximum and $+1.6 \mathrm{~W} \mathrm{~m}^{-2}$ today. The forcing from the $\mathrm{CH}_{4}$ changes is considerably smaller, reaching about $+0.5 \mathrm{~W} \mathrm{~m}^{-2}$ today.

The warming commitment from today's radiative forcing by $\mathrm{CO}_{2}$ and $\mathrm{CH}_{4}$ of $2.1 \mathrm{~W} \mathrm{~m}^{-2}$ is readily evaluated from equation (1). For a mid-range climate sensitivity of $3^{\circ} \mathrm{C}$, one expects an equilibrium warming of $1.7^{\circ} \mathrm{C}$ relative to pre-industrial conditions. However, a considerable part of the greenhouse gas forcing is offset by the cooling influence of aerosols and the climate system lags the forcing due to the large thermal inertia of the ocean.

Figure 2 puts the radiative forcing from greenhouse gases in the context of the known perturbations for the Last Glacial Maximum and today. The increase in albedo due to larger ice sheets is the largest individual forcing at the Last Glacial Maximum, whereas changes associated with the biogeochemical system (greenhouse gases, dust, vegetation changes) are responsible for more than half of the total Last Glacial Maximum forcing. Today's total radiative forcing is the result of partly offsetting contributions from the well-mixed greenhouse gases $\left(\mathrm{CO}_{2^{\prime}} \mathrm{CH}_{4^{\prime}}, \mathrm{N}_{2} \mathrm{O}, \mathrm{CFCs}\right)$, stratospheric and tropospheric ozone, a mix of different aerosols, and changes in land use and solar irradiance. $\mathrm{CO}_{2}$ is clearly the most important agent among the well-mixed greenhouse gases. Over the coming decades, atmospheric $\mathrm{CO}_{2}$ will become of even greater relative importance, as emitted $\mathrm{CO}_{2}$ accumulates over time in the climate system and recent sulfur emission control measures limit the growth in (cooling) aerosol forcing.

\section{References}

Joos, F., I. C. Prentice, S. Sitch, R. Meyer, G. Hooss, G. K. Plattner, S. Gerber, and K. Hasselmann, Global warming feedbacks on terrestrial carbon uptake under the Intergovernmental Panel on Climate Change (IPCC) emission scenarios, Global Biogeochemical Cycles, 15, 891-907, 2001.

Ramaswamy, V., O. Boucher, J. Haigh, D. Hauglustaine, J. Haywood, G. Myhre, T. Nakajima, G. Y. Shi, and S. Solomon, Radiative forcing of climate change. Climate Change 2001: The Scientific Basis. Contribution of Working Group I to the Third Assessment Report

\begin{tabular}{|c|c|c|}
\hline agent & equation & $C_{o}$ \\
\hline $\mathrm{CO}_{2}$ & $\mathrm{RF}=5.35 \mathrm{~W} \mathrm{~m}^{-2} \ln \left(\mathrm{CO}_{2} / \mathrm{CO}_{2, o}\right)$ & $278 \mathrm{ppm}$ \\
\hline $\mathrm{CH}_{4}$ & $\begin{array}{l}\mathrm{RF}=0.036 \mathrm{~W} \mathrm{~m}^{-2}\left(\sqrt{\mathrm{CH}_{4}}-\sqrt{\mathrm{CH}_{4,0}}\right) \\
-\left(f\left\lfloor\mathrm{CH}_{4,}, \mathrm{~N}_{2} \mathrm{O}_{0}\right\rfloor-f\left\lfloor\mathrm{CH}_{4,0,}, \mathrm{~N}_{2} \mathrm{O}_{0}\right\rfloor\right.\end{array}$ & $742 \mathrm{ppb}$ \\
\hline $\mathrm{N}_{2} \mathrm{O}$ & $\begin{array}{l}\mathrm{RF}=0.12 \mathrm{~W} \mathrm{~m}^{-2}\left(\sqrt{\mathrm{N}_{2} \mathrm{O}}-\sqrt{\mathrm{N}_{2} \mathrm{O}_{0}}\right) \\
-\left(f\left\lfloor\mathrm{CH}_{4, o}, \mathrm{~N}_{2} \mathrm{O}\right\rfloor f\left\lfloor\mathrm{CH}_{4,0,}, \mathrm{~N}_{2} \mathrm{O}_{0}\right\rfloor\right.\end{array}$ & $272 \mathrm{ppb}$ \\
\hline CFC-11 & $\mathrm{RF}=0.25 \mathrm{~W} \mathrm{~m}^{-2}\left(C F C-11-C F C-11_{0}\right)$ & $0 \mathrm{ppt}$ \\
\hline $\mathrm{CFC}-12$ & $\mathrm{RF}=0.32 \mathrm{~W} \mathrm{~m}^{-2}\left(C F C-12-C F C-12_{0}\right)$ & $0 \mathrm{ppt}$ \\
\hline
\end{tabular}

Table 1: Equations to calculate radiative forcing relative to a pre-industrial (1750 A.D.) reference concentration $\left(C_{0}\right)$. Overlap in absorption bands between $\mathrm{N}_{2} \mathrm{O}$ and $\mathrm{CH}_{4}$ is taken into account using the overlap function $f(M, N)=0.47 \ln \left(1+2.01 \times 10^{-5}(M N)^{0.75}+5\right.$. $\left.31 x-M(M N)^{1.52}\right)$. For practical purposes, this correction term can be neglected. Formulations for additional greenhouse gases can be found in Joos et al. (2001) and Ramaswamy et al. (2001). 

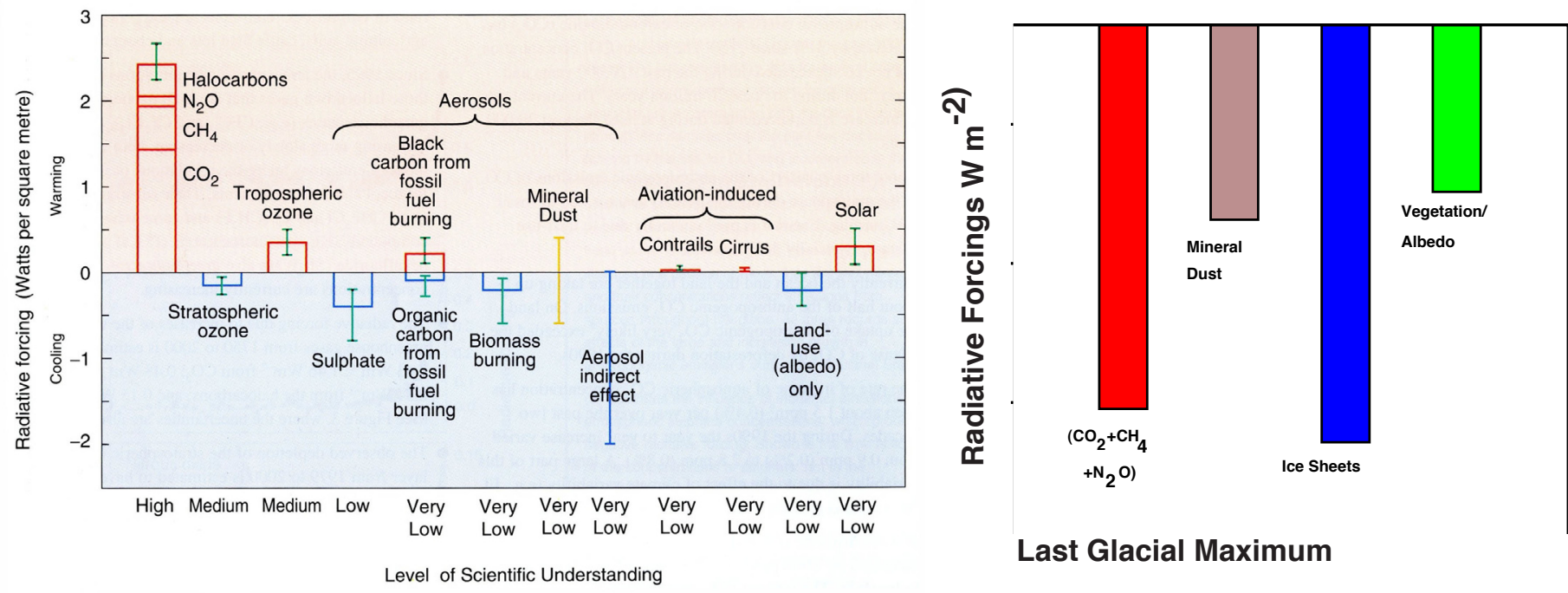

Figure 2: Radiative forcing for today (Ramaswamy et al., 2001, IPCC report 2001) (left) and the Last Glacial Maximum (right) relative to 1750 A.D. for the range of known perturbations.

of the Intergovernmental Panel on Climate Change, edited by Houghton, J. T., Y. Ding, D. J. Griggs, M. Noguer, P. J. van der Linden, X. Dai, et al., Cambridge University Press, 349-416, 2001.
Stauffer, B., J. Flückiger, E. Monnin, M. Schwander, J. M. Barnola, and J. Chappellaz, Atmospheric $\mathrm{CO}_{2}, \mathrm{CH}_{4}$ and $\mathrm{N}_{2} \mathrm{O}$ records over the past 60,000 years based on the comparison of different polar ice cores. Annals of Glaciology, 35, 202-208, 2002.

\section{Solar forcing of climate change: Current status}

\section{Judith Lean}

\section{E.0. Hulburt Center for Space Research, Naval Research Laboratory, Washington, DC, USA. jlean@ssd5.nrI.navy.mil}

\section{Solar Irradiance Variability}

\section{Observations}

Space-based radiometers have monitored the Sun's total irradiance since 1978 , providing a record that now covers more than two 11-year solar activity cycles. Composite irradiance time series have been constructed by combining individual measurements after first adjusting for instrumental differences. In the irradiance composite shown in Figure 1 (upper panel), levels are comparable (within $0.01 \%$ ) in the two most recent cycle minima, which suggests the absence of a secular trend in recent times (Fröhlich and Lean, 2004). This record agrees with models that parameterise irradiance variations in terms of sunspot and faculae, which respectively deplete and enhance local radiative output (Fröhlich and Lean, 2004).

Since 2003, instruments on SORCE (Solar Radiation and Climate Experiment) have been monitoring the Sun's total and spectral irradiance across ultraviolet, visible and near infrared regions, for the first time from space. On average, SORCE measures absolute total solar irradiances $5.2 \mathrm{Wm}^{-2}$ $(0.4 \%)$ lower than other radiometers. As expected, solar irradiance varies at all wavelengths in ways that reflect the different solar origins of the emissions from a range of temperatures and structures within the solar atmosphere. Maximum energy changes occur at wavelengths from 400 to $500 \mathrm{~nm}$, whereas fractional changes are greatest at UV wavelengths, where the energy change is, however, considerably smaller. A model that linearly combines sunspot and facular effects, incorporating the spectral dependence of their contrasts, provides close (but imperfect) tracking of both total and spectral irradiance variations (Lean et al., 2005).

\section{Reconstructions}

Until recently, reconstructions of historical solar irradiance assumed that longer-term variations are larger than during the 11-year cycle, since proxy indicators of solar activity (the aa index, ${ }^{14} \mathrm{C}$ and ${ }^{10} \mathrm{Be}$ cosmogenic isotopes in tree rings and ice cores, and the range of variability in Sun-like stars) suggest that the Sun is capable of a greater range of activity than witnessed in recent times. With this approach, total irradiance during the 17th century Maunder Minimum is reduced in the range of 0.15 to $0.4 \%$ ( 2 to $5 \mathrm{Wm}^{-2}$ ) below contemporary cycle minima values. But stellar data have been reassessed, instrumental drifts are suspected in the $a a$ index, and it has been shown that long-term trends in the $a a$ index and cosmogenic isotopes (generated by the open magnetic flux from the Sun that pervades the heliosphere) do not necessarily imply equivalent long-term trends in solar irradiance (which track closed magnetic flux within the solar atmosphere). In the irradiance reconstruction shown in Figure 1 (bottom panel), which is based on solar considerations alone (Wang, Lean and Sheeley, 2005), the amplitude of the background component is 0.27 times that of Lean (2000). As a result, total solar irradiance, increases about $\sim 0.5 \mathrm{Wm}^{-2}$ from the Maunder Minimum to the present-day quiet Sun. The larger amplitude secular irradiance changes of the initial reconstructions are therefore likely upper limits of long-term solar irradiance variability.

\section{Climate Response to Solar Variability \\ Mechanisms}

Distinctly different mechanisms are surmised for climate's response to solar radiative forcing. Direct "short-wave" heating of the surface, ocean and troposphere generates 